\title{
The Formation of Florists' Social Media-Based Brand Communities and Its Causal Relationship with Users' Knowledge, Personal Experience, and Florists' Brand Equity
}

\author{
Li-Chun Huang \\ Department of Bio-Industry Communication and Development, National \\ Taiwan University, \#1, Sec.4, Roosevelt Road, Taipei 10617, Taiwan
}

Additional index words. confirmatory factor analysis, flower, SEM, structural equation modeling

\begin{abstract}
As social media penetration has reached more than half of the eligible populations for most of the countries in the world, many florists are thinking of ways of converting their social media fan base into a virtual brand community that can bring numerous benefits to the florists. As relevant topics are rarely investigated in the academic domain of floriculture, this study seeks to address this deficiency. The objectives of this study were 1) to examine the possibility of converting the florists' social media fan base into a virtual brand community, and 2) to investigate the influence of users' knowledge of and personal experience with the florist on the formation of the florists' social media-based brand communities, as well as the subsequent influence on the florists' brand equity. The statistical results of the descriptive statistical analysis and structural equation modeling (SEM) indicate that the florists' social media fan base has revealed the markers of brand communities, demonstrating the potential that exists for building the florists' virtual brand communities from their social media fan base. These statistical results also show that the users' knowledge of the florist is one of the key elements assisting in the conversion of the florist's fan base into a virtual brand community for the florist, and subsequently enhances the users' commitment toward the florist's brand. Even though the influence of the users' personal experience with the florist on the formation of the florist's social media-based brand community is not proved, it is found to be highly correlated with the users' knowledge of the florist. Based on the study's findings, strategies for driving the formation of florists' social media-based brand communities are also provided.
\end{abstract}

Social media marketing is a marketing approach by which products or brands are promoted or sold using a social media platform, such as Facebook, YouTube, Instagram, etc. (Akar and Topçu, 2011; Drury, 2008). Many florists have been selling flowers by using this marketing approach. For example, depending on the regions, between $39 \%$ and $69 \%$ of the florists in the United States have adopted social media as a tool for selling flowers to consumers (Prince and Prince, 2014); the environmental horticulture industry in the United States considers social media to be an important advertising channel given that its enterprisers spent

Received for publication 25 Mar. 2020. Accepted for publication 29 Apr. 2020.

Published online 1 June 2020

This research was funded by the Ministry of Science and Technology of Taiwan under the grants MOST 107-2410-H-002-198 and MOST 108-2410-H-002190-SSS.

L.-C.H. is the corresponding author. E-mail: lihuang@ntu.edu.tw.

This is an open access article distributed under the CC BY-NC-ND license (https://creativecommons. org/licenses/by-nc-nd/4.0/).
$43 \%$ of their online advertising budget on social media, websites, and newsletters (Torres et al., 2019). It is clear that improving the effectiveness of the application of social media in flower retailing is a topic worthy of attention in the floral industry.

Social media has several functions in marketing due to their Web.2.0-based information technology, i.e., in terms of serving as a platform for mutual communications between enterprises and consumers, developing new customers, enhancing brand awareness and word-of-mouth, etc. (Abed et al., 2015; Akar and Topçu, 2011; Drury, 2008; Fuchs, 2014; Kaplan and Haenlein, 2010). However, with regard to the commercial competition in the current social media era, the most pressing issue concerns how social media can be applied as a platform to unite users and subsequently transform those users into a brand community to support the growth of the brand (Laroche et al., 2012).

Brand communities are one of the many different types of consumer communities, and are formed by groups of consumers who love particular brands. As the structure of a consumer group is more typical as a brand community, the more favorable will that consumer group be toward the development of the brand, because the members of that consumer group are usually highly loyal to that brand. Therefore, these members are usually the potential opinion leaders who influence other consumers' attitudes and purchase intentions toward the brand. These members are also more likely to generate word-of-mouth for that brand, which is conducive to expanding the brand's reputation among the consumers (Muniz and O'Guinn, 2001). The same principles also apply among virtual brand communities. The more that the consumers engage in a virtual brand community, the more likely it is that they will have increasingly positive attitudes toward the social media advertisements for that brand, and will consume more of the products (Chi, 2011; Goh et al., 2013).

The formation of a brand community is measured in accordance with various community markers, i.e., a "shared consciousness," "shared rituals and traditions," and an "obligation to society" (Muniz and O'Guinn, 2001; Tajfel, 1982; Zaglia, 2013). In other words, if a brand's fan group exhibits the markers of communities, the fan group can be said to have become or to be becoming a brand community for that brand. Scholars have observed that the social media fan bases for some industries exhibit the community markers of a shared consciousness, shared rituals and traditions, and an obligation to society, implying the functionality of social media in converting users into a virtual brand community. The more that the fan base possesses such community markers, the more likely it is that the fans will engage in valuecreation activities to further promote the brand (Laroche et al., 2012). A social media-based brand community also has a positive effect on building consumers' relationships with the company, products, and brands, as well as with other consumers (Laroche et al., 2013).

Although social media is believed to have great potential in fostering virtual brand communities, the factors that drive users to engage in the florists' social media-based brand communities remain unknown for the floral industry. Simon and Tossan (2018) argued that social interactions between brands and consumers increase consumers' intimacy with the brand, and thereby in turn increase the consumers' appreciation for the enterprise or brand. Algesheimer et al. (2005) discovered that a positive brand relationship facilitates consumers' identification with the brand community, and thus results in consumers being more likely to engage in the brand community, while also lowering consumers' negative perceptions toward the normative community pressure. According to the findings for other industries as discussed previously, it is very likely to be the case in the floral industry that users' personal experiences with a florist will influence their engagement in the florist's social mediabased brand community, while at the same time increasing the brand equity of the florist. 
Besides users' experiences with the florists, the users' knowledge of the florists may also influence the formation of the florists' social media-based brand communities. As virtual communities have become the major platform for consumers to exchange information, individuals who are more knowledgeable about a subject are expected to have more opportunities to interact with others through social media. Besides, they may have a higher degree of interest in or more experience with that subject, and thus be more capable of serving as an opinion leader in a consumer community to influence other consumers' perceptions and attitudes toward that subject. Because of their higher loyalty and greater social interaction, such individuals will consequently have a better social network in that virtual environment, and thus may be more likely to keep their membership in that community. Therefore, as social media serves as a source for consumers to acquire information on the floral industry (Russell Research, 2016), it is very likely that users' knowledge of a certain florist will influence the formation of that florist's social media-based brand community.

Although official social media pages have the potential for converting users into brand communities, numerous flower retailers still favor social media as a platform for information disclosure, thereby neglecting the function that social media can achieve in brand management. For example, Huang and Chen (2018) investigated the typology of florists' Facebook posts and discovered that more than $50 \%$ of those posts were aimed at introducing products or services to consumers, with few posts being used to cultivate consumers' interactions with florists or group members within the fan base. Even though social media can function as an important platform for florists to manage their brands, scholars rarely investigate related issues in the academic domain of floriculture. This study thus seeks to address this deficiency. The objectives of this study were to 1) explore the potential of converting the florists' social media fan base into a social media-based brand community, and 2) investigate the influence of users' knowledge of and personal experience with a florist on the formation of a virtual brand community for the florist, as well as the subsequent influence on the brand equity of that florist. Because Facebook is the most popular social network worldwide (Statista, 2019), these study objectives are assessed in a setting where Facebook is used by the florists.

Approximately $80 \%$ of florists in Taiwan are located in metropolitan areas, but because of the increasing cost of renting a store, many florists have relocated their stores farther away from the town center, and thus online flower shops have become an alternative plan for those florists to continue their businesses (Yuan, 2010). Because Facebook is a very popular social medium in Taiwan, in that $80.5 \%$ of its entire population are Facebook users (NapoleonCat, Inc., 2019), many of the florists have started their online businesses by opening a brand page on Facebook. Therefore, the samples used in this study are valid in examining the questions proposed in this study, and the empirical findings of this study should be helpful to those florists who are interested in improving their online businesses via social media.

\section{Materials and Methods}

Sampling. To recruit users who interacted with the Facebook brand pages administered by florists located in Taiwan to participate in the survey, the researcher first searched Facebook to find those florists who owned a Facebook brand page using the keywords "flower" and "flower shop" in traditional Chinese as search entries. Then the researcher contacted these florists via Facebook and asked them to post an announcement for subject recruitment on their Facebook brand pages for the purposes of this study. These florists also messaged their fans on Facebook Messenger regarding this study and encouraged them to participate. The recruitment announcement contained the URL link through which the fans of those florists could access the electronic questionnaire designed for this study. Subjects were rewarded with a voucher of NT\$100 for shopping at convenience stores after completing the questionnaire.

The survey took place from 3 May to 4 Nov. 2018. A total of 500 subjects participated in the survey. After removing the invalid questionnaires, namely, the questionnaires that had been completed by users younger than 18 , or where more than three of the questions in the Likert scale remained unanswered, or where either the age or gender information was not provided, a total of 410 valid questionnaires remained for the statistical analysis.

Questionnaire design. An online questionnaire was developed as an instrument to collect data. In the survey, subjects were asked to respond to these questions according to their practical contact with the florist that owned the brand page that they followed. The questionnaire was composed of three sections. The first section consisted of a consent letter informing participants of the purpose of the survey, the legal protection of their personal data, and their authorized rights in the survey. The second section was the main body of the questionnaire that constituted the scales for measuring the variables or constructs in this study. The third section of the questionnaire queried the sociodemographics of the subjects, including their age, gender, education, occupation, and monthly income. The definitions and measurement scales for the variables or constructs were as follows:

1. "User experience" was defined as users' perceptions or feelings derived from their interactions with or direct observations of the florists. In this study, it was assessed with the scales of "I have a good interaction with this florist," "I have a pleasant purchasing experience with this florist," and "I am positively impressed by this florist," which were developed based on the theoretical concept of consumer experience (Schmitt and Zarantonello, 2013).

2. "User knowledge" referred to users' subjective knowledge of the florist who owned the brand page followed by the users. It was measured with the scales of "I know the history of this florist well," "I am familiar with the owner of this flower shop," and "I know the products and services provided by this florist well." The scales were modified based on the theoretical concept of consumer knowledge (Brucks, 1985; Park et al., 1994)

3. "Formation of florist social mediabased brand community" referred to the extent to which a florist's fan base had been transformed into a social media-based brand community for that florist, as indicated by the community markers of shared consciousness, shared rituals and traditions, and moral responsibility, based on the theory proposed by Laroche et al. (2012). A "shared consciousness" indicated that the community members were able to identify with and generate a sense of attachment and belonging to the community group, and were able to identify the differences between the community group and other groups. It was measured using the scales "I and other followers of this florist's Facebook brand page identify with each other as part of the same group," "I and other followers of this florist's Facebook brand page feel that we belong to the same group," and "Our fan base has its own unique characteristics that are different from those of other florists." "Shared rituals and traditions" referred to an in-depth coordination between group members contributing to the cultivation of habits or traditions exclusive to that group, as well as norms that members jointly adhered to. Accordingly, scales for its measurement were worded as "The florist's Facebook fan base I belong to has established its private conventions," "The florist's Facebook fan base I belong to has established its exclusive rituals," and "The florist's Facebook fan base I belong to has established its own habits." "Moral responsibility" referred to the sense of responsibility that community members had recognized for the community, and was measured using the scales "Followers of this florist's Facebook brand page are enthusiastic to help one another," "Followers of this florist's Facebook brand page endeavor to ensure the existence of their fan base," and "I am willing to fulfill my responsibility to the florist's Facebook fan base that I belong to." 
4. "Brand equity" referred to the overall marketing effects uniquely attributable to the brand. Modified from Zaglia's (2013) study on virtual brand communities, the florists' brand equity in this study was measured using consumerperceived quality and loyalty to the florist. Consumer-perceived quality was measured with the scales "I think this florist offers great products and services," "This florist offers excellent products and services," and "The quality of the florist's products and services is highly consistent," whereas brand loyalty was measured with the scales "I will repurchase products from this florist," "I will buy horticultural products only from this florist," and "I am willing to recommend this florist to other consumers."

All of the preceding items were measured using a 5-point Likert scale $(1=$ strongly disagree; 2 = disagree; $3=$ neutral; 4 = agree; $5=$ strongly agree).

A pretest was conducted with 30 subjects, who were recruited from the targeted population, i.e., users of florists' Facebook brand pages, to ensure the appropriateness of the questionnaires in terms of the number of items, semantic clarity, and time required to complete the questionnaires.

Statistical analysis. This study processed the analysis of SEM with a two-step approach to examine the effect of users' knowledge and personal experience with florists on the formation of the florists' social media-based brand communities, and the subsequent influence on the brand equity of florists (Anderson and Gerbing, 1988). The assumption of multivariate normality is a basic requirement for the statistical analysis of SEM. Therefore, the normality of the observations was evaluated with the values for skewness and kurtosis before the statistical analysis of SEM (Hair et al., 2010).

1. The confirmation of the measurement model. The measurement model referred to the proposed structure of the scales designed to measure the latent variables or constructs. In this study, a confirmatory factor analysis with maximum likelihood estimation was performed using AMOS 24 to estimate the parameters of goodness-of-fit for the researcher to assess the model-fit of the measurement model. All these procedures enabled the researcher to evaluate the validation of the measurement model for measuring the context in terms of what the variables or constructs actually mean (Hair et al., 2010).

2. The analysis of the structural model. Once the model-fit of the measurement model was confirmed, the hypothesized structural model profiling the causal relationships among users' knowledge, personal experience, the formation of the florist's social media-based brand community, and the brand equity of the florists was tested using SEM with maximum likelihood estimation, thereby confirming the paths in the structural model on the basis of the statistical significance, goodness-of-fit, and predictive power of the model (Anderson and Gerbing, 1988; McDonald and Ho, 2002). In the process, the model-fit of the structural model was tested using a goodness-of-fit test. This allowed the researcher to verify whether the proposed structural model truthfully reflected the actual relationship condition of the empirical data (Kline, 2015).

3. Model-fit evaluation. To comply with the two-step approach of the SEM analysis, this study evaluated the model-fit for both the measurement and structural models separately using the goodness-of-fit test. There have been various indices suggested for the measure of the overall goodness-of-fit of the SEM models. In this study, the researcher used the following parameters, which are considered by most scholars to be applicable to both the measurement and structural models (Bagozzi and Yi, 1988; Hair et al., 2010).

1) Absolute fit indices: Absolute fit is usually indexed with $\chi^{2}, \chi^{2} / \mathrm{df}$, goodness-of-fit index (GFI), adjusted GFI (AGFI), root mean square error of approximation (RMSEA), and root mean square residual (RMR). As $\chi^{2}$ is highly sensitive to the complexity of the models, it can be substituted with $\chi^{2} / \mathrm{df}$ to resist the effect of model complexity. Schumacker and Lomax (2004) suggested that $\chi^{2} / \mathrm{df}$ should be $<5$. GFI is also a parameter used to evaluate the explanatory power of the proposed model for the empirical data, similar to the function of $R^{2}$ in regression analysis (Hair et al., 2010). The AGFI is derived by adjusting the GFI according to the number of df. GFI or AGFI should be $>0.8$ for a qualified goodness-of-fit (Doll et al., 1994; MacCallum and Hong, 1997). The RMSEA is used to test the variance between the proposed model and saturated model with a perfect fit, and so lower values are preferred, particularly those $<0.08$ (Hair et al., 2010). If the index exceeds 0.10 , the model is considered unsatisfactory (Browne and Cudeck, 1993).

Residual indices refer to the parameters of the RMR or standardized RMR (SRMR), which are used to verify whether the setting of a particular parameter in the proposed model is ideal. This verification helps determine whether the lack-of-fit of the entire model is caused by the lack-of-fit of a particular measurement model. Hair et al. (2010) asserted that the RMR value should be low, preferably $<0.05$. SRMR differs from RMR in that it is standardized and easier to interpret. SRMR values range from 0 to 1 ; a value $<0.08$ indicates that the model has excellent goodness-of-fit (Hu and Bentler, 1999). If the index exceeds 0.10 , the model is considered to be unsatisfactory (Browne and Cudeck, 1993).

2) Incremental fit indices: Incremental fit indices generally refer to the normed fit index (NFI) and non-NFI (NNFI). These indices are used to evaluate increases in the goodness-of-fit of a proposed model compared with the null hypothesis model. The greater the increase, the more superior the proposed model becomes. Because the NFI and NNFI are used to indicate the degree of improvement in a hypothesized model compared with a null hypothesis model, large values are preferred, particularly values >0.9 (Bentler and Bonett, 1980; Jöreskog and Sörbom, 1996).

3) Parsimonious fit indices: Parsimonious fit is one of the measures of overall goodness-of-fit that attempts to correct for any overfitting of the model and evaluates the parsimony of the model compared with the goodness-of-fit (Hair et al., 2010). The comparative fit index (CFI) is the most suggested index for the parsimonious fit measure. This index ranges from 0 to 1 . A value of 0.9 or greater is considered an acceptable fit (Garver and Mentzer, 1999).

\section{Results and Discussion}

Profile of samples. There were 410 valid responses returned from the online questionnaire survey. Among the subjects, $65.1 \%$ were women, and men accounted for $34.9 \%$ (Table 1); most were between 20 and 29 years old $(42.2 \%)$, followed by those between 30 and 39 years old $(39.5 \%)$. Most of the subjects had acquired a bachelor's degree $(59.5 \%)$, followed by those who had graduated from high school or vocational high school $(27.3 \%)$. With regard to the subjects' occupations, most worked in the service industry $(51.2 \%)$, followed by those in the industrial, mining, and manufacturing sectors $(16.3 \%)$. With regard to income, most of the subjects had a monthly income of $\approx$ NT $\$ 32,001$ to $42,000(34.1 \%)$, followed by NT $\$ 22,000$ to 32,000 (33.4\%). Overall, the sample skewed toward a younger, female population resembling Facebook's advertising audience and flower consumers in age and gender, ensuring the subjects' validation for being the sample used in this study. Previous studies have indicated that the age groups of the 20s and 30s share the greatest portion of Facebook's global addressable advertising audience (Datareportal, 2019). These are also the age groups that possess the greatest usage rates for Facebook in many 
countries, including Taiwan and the United States (NapoleonCat, Inc., 2019; OrtizOspina, 2019). In terms of the gender profile of flower purchasers, previous studies have shown that women account for a higher percentage of purchases (Schimmenti et al., 2013; Tzavaras et al, 2010).

Test of multivariate normality. The data agreed with the assumption of multivariate normality required for the statistical analysis of SEM with the statistical results being presented in Table 2. These results indicate that across the variables, the absolute values of skewness ranged from 0.181 to 0.827 , whereas those of kurtosis ranged from 0.021 to 1.039 . In general, when the absolute value of skewness is $>3$ or that of kurtosis is $>10$, the observations are not considered to be normally distributed (Kline, 2015). Therefore, the statistical results of the skewness

Table 1. The sociodemographics of samples based on the data generated from 410 valid online questionnaires sampled during the period from 3 May 2018 to 4 Nov. 2018 from the fan base of the Facebook brand pages established by the florists located in Taiwan.

\begin{tabular}{|c|c|c|c|}
\hline Variable & Category & Size & Percentage $(\%)$ \\
\hline \multirow[t]{2}{*}{ Gender } & Male & 143 & 34.9 \\
\hline & Female & 267 & 65.1 \\
\hline \multirow[t]{6}{*}{ Age } & $18-19$ & 4 & 1.0 \\
\hline & $20-29$ & 173 & 42.2 \\
\hline & $30-39$ & 162 & 39.5 \\
\hline & $40-49$ & 34 & 8.3 \\
\hline & $50-59$ & 30 & 7.3 \\
\hline & $\geq 60$ & 7 & 1.7 \\
\hline \multirow[t]{9}{*}{ Occupation } & Agriculture, forestry, fishery, husbandry production & 23 & 5.6 \\
\hline & Industry, mining, manufacturing & 67 & 16.3 \\
\hline & Commercials or service business & 210 & 51.2 \\
\hline & Government officials, military service, teaching & 31 & 7.6 \\
\hline & Students & 35 & 8.5 \\
\hline & Home maker & 18 & 4.4 \\
\hline & Retired & 2 & 0.5 \\
\hline & Unemployed & 10 & 2.4 \\
\hline & Others & 14 & 3.4 \\
\hline \multirow[t]{4}{*}{ Education } & Junior high school & 7 & 1.7 \\
\hline & Senior high school & 112 & 27.3 \\
\hline & College & 244 & 59.5 \\
\hline & Graduate school & 47 & 11.5 \\
\hline \multirow[t]{7}{*}{ Monthly income } & NT $\$ 22,000$ or less & 64 & 15.6 \\
\hline & NT $\$ 22,001-32,000$ & 137 & 33.4 \\
\hline & NT $\$ 32,001-42,000$ & 140 & 34.1 \\
\hline & NT $\$ 42,001-52,000$ & 39 & 9.5 \\
\hline & NT $\$ 52,001-62,000$ & 13 & 3.2 \\
\hline & NT $\$ 62,001-72,000$ & 6 & 1.5 \\
\hline & $\geq \mathrm{NT} \$ 72,001$ & 11 & 2.7 \\
\hline
\end{tabular}

and kurtosis analyses in this study indicated that the variables examined were all normally distributed, thereby qualifying for the statistical analyses planned in this study, and ensuring the quality of the statistical results (Hair et al., 2010).

The current development status of the florists' social media-based brand communities. The outcomes of the descriptive statistical analysis revealed that the averages of the shared consciousness, shared rituals and traditions, and obligation to society appearing in relation to the florists' social mediabased fan groups were respectively 3.63, 3.62 , and 3.68 on a 5 -point Likert scale. This indicated that the florists' social media pages have developed into a brand community to some extent, but not to a great degree.

Confirmation of measurement model. A confirmatory factor analysis with maximum likelihood estimation was conducted to assess the model-fit of the measurement model using multiple goodness-of-fit indices. The statistical results indicated that the measurement model had superior goodness-of-fit, except for one of the community markers. The measurement model for community markers was originally composed of nine scales, but the goodness-of-fit test yielded an RMSEA value that was $>1$, which exceeded the tolerable range of $<0.1$, indicating a lack-of-fit. After revising the measurement scales to four according to the modification index generated by the confirmatory factor analysis, the revised model reached an optimal goodness-of-fit with an RMSEA value of 0.057 , fulfilling the designated requirement. The statistical results of the goodness-of-fit test are reported in Table 3 . Thereafter, the measure for the community markers was adjusted in the analysis of the structural model that followed.

Table 2. Statistical results of the normal distribution test for the databased on 410 valid online questionnaires sampled during the period from 3 May 2018 to 4 Nov. 2018 from the fan base of the Facebook brand pages established by the florists located in Taiwan.

\begin{tabular}{|c|c|c|c|c|}
\hline Variables and scales & Means & SD & Skewness & Kurtosis \\
\hline User knowledge & 3.297 & 0.047 & -0.298 & -0.164 \\
\hline 1. I know the history of this florist well & 3.15 & 0.050 & -0.215 & -0.373 \\
\hline 2. I am familiar with the owner of this flower shop & 3.18 & 0.058 & -0.269 & -0.797 \\
\hline 3. I know the products and services provided by this florist well & 3.56 & 0.048 & -0.594 & 0.263 \\
\hline Personal experience & 3.777 & 0.039 & -0.483 & 0.209 \\
\hline 1. I have a good interaction with this florist & 3.60 & 0.046 & -0.267 & -0.408 \\
\hline 2. I have a pleasant purchasing experience with this florist & 3.76 & 0.045 & -0.485 & 0.057 \\
\hline 3. I am positively impressed by this florist & 3.97 & 0.041 & -0.652 & 0.408 \\
\hline Community markers & 3.638 & 0.042 & -0.398 & -0.197 \\
\hline 1. I and other followers of this florist's Facebook brand page identify with each other as part of the same group & 3.72 & 0.047 & -0.549 & -0.021 \\
\hline 2. I and other followers of this florist's Facebook brand page feel that we belong to the same group & 3.57 & 0.049 & -0.392 & -0.277 \\
\hline 3. Our fan base has its unique characteristics that are different from those of other florists & 3.61 & 0.047 & -0.482 & 0.063 \\
\hline 4. The florist's Facebook fan base I belong to has established its private conventions & 3.57 & 0.050 & -0.353 & -0.422 \\
\hline 5. The florist's Facebook fan base I belong to has established its exclusive rituals & 3.63 & 0.048 & -0.366 & -0.326 \\
\hline 6.The florist's Facebook fan base I belong to has established its own habits & 3.65 & 0.048 & -0.576 & 0.118 \\
\hline 7. Followers of this florist's Facebook brand page are enthusiastic to help one another & 3.65 & 0.051 & -0.573 & 0.022 \\
\hline 8. Followers of this florist's Facebook brand page endeavor to ensure the existence of their fan base & 3.70 & 0.051 & -0.638 & 0.102 \\
\hline 9. I am willing to fulfill my responsibility to the florist's Facebook fan base that I belong to & 3.70 & 0.048 & -0.524 & 0.061 \\
\hline Perceived quality & 4.068 & 0.033 & -0.555 & 0.691 \\
\hline 1. I think this florist offers great products and services & 4.06 & 0.035 & -0.585 & 1.039 \\
\hline 2. This florist offers excellent products and services & 4.08 & 0.037 & -0.492 & 0.181 \\
\hline 3. The quality of the florist's products and service is highly consistent & 4.06 & 0.036 & -0.468 & 0.252 \\
\hline User loyalty & 3.871 & 0.037 & -0.333 & 0.077 \\
\hline 1. I will repurchase products from this florist & 4.07 & 0.039 & -0.660 & 0.455 \\
\hline 2. I will buy horticultural products only from this florist & 3.42 & 0.054 & -0.181 & -0.838 \\
\hline 3. I am willing to recommend this florist to other consumers & 4.12 & 0.040 & -0.827 & 0.927 \\
\hline
\end{tabular}


After the overall model-fit was confirmed, the unidimensionality and reliability for each construct were evaluated. The unidimensionality was assessed with factor loadings (Hair et al., 2010). The standardized estimates of scales' factor loadings on the variables or constructs ranged between 0.679 and 0.901 , with none exceeding 1 or 0.95 . Meanwhile, the variances of the estimated errors among the scales were positive, ranging between 0.104 and 0.645 , with no offending estimates being found (Table 4). All these findings proved the superior quality of the measurement models (Bollen, 1989; Hair et al., 2010). After that, the reliability and validity of the measurement model were assessed. At first, the models' internal consistency, as indicated by Cronbach's $\alpha$, and composite reliability were assessed. The Cronbach's $\alpha$ values ranged between 0.751 and 0.909 , fulfilling the requirement of $\geq 0.7$ (George and Mallery, 2003). The measures of composite reliability ranged between 0.804 and 0.949 , conforming to the suggested value of $\geq 0.6$ (Fornell and Larcker, 1981). Accordingly, the measures of the variables or constructs were proven to be reliable.

The construct validity of the measurement model was verified by performing convergent and discriminant validity tests. The average variance extracted (AVE) of the variables or constructs ranged between 0.578 and 0.860 , conforming to the suggested value of $\geq 0.5$ (Bagozzi and Yi, 1988), thereby ensuring the superior convergent validity of the measurement model (Table 4). Discriminant validity was assessed on all possible pairs of variables or constructs using the standard proposed by Fornell and Larcker (1981), that is, the latent variable or construct should share more variance with its assigned indicators than with any other latent variables or constructs, being indexed by the statistics that the square root of the AVE of each construct should be higher than the construct's highest correlation with any other latent constructs. The statistical results are presented in Table 5, and support the discriminant validity of the measurement model used in this study.

The structural model. After the reliability and validity of the measurement model were confirmed, the structural model used to determine the causal relationship between the latent variables or constructs was assessed with structural equation modeling using maximum likelihood estimation. The model-fit was examined with multiple indices, as shown in Table 6. Overall, the fit statistics matched the requirements on the measures of absolute fit (GFI, SRMR) and parsimonious fit (CFI), as well as being marginally supported by the measure of incremental fit (NFI), indicating that the structural model provided a good fit to the data (Table 6).

The goodness-of-fit test confirmed the usefulness of the structural model in illustrating the actual causal relationship among the latent variables and/or constructs. The statistical results of the SEM analysis indicated that all the path coefficients for the hypothesized relationships in the structural model were significant, except for the one for the relationship between users' experience with the florists and the formation of the florist's social media-based brand community $(\beta=0.087, P=0.476)$, as well as the one for the relationship between the formation of the florist's social media-based brand community and users' perceived quality for the florist owing the Facebook page $(\beta=0.022$, $P=0.634)$, as presented in Table 7 and Fig. 1 .

The statistical results revealed the importance of users' knowledge in converting the florist's social media fan base into an online brand community, of users' knowledge of a florist significantly facilitating the formation of that florist's social media-based brand

Table 3. Statistical results of the goodness-of-fit test for the measurement model based on 410 valid online questionnaires sampled during the period from $3 \mathrm{May}$ 2018 to 4 Nov. 2018 from the fan base of the Facebook brand pages established by the florists located in Taiwan.

\begin{tabular}{|c|c|c|c|c|c|c|}
\hline Model-fit indices & Suggested value & User knowledge & Personal experience & Community markers & Perceived quality & User loyalty \\
\hline$\overline{\chi^{2} / \mathrm{df}}$ & $<5.0$ & 1.632 & 3.712 & 2.312 & 0.982 & 0.349 \\
\hline GFI & $>0.8$ & 0.997 & 0.994 & 0.995 & 0.998 & 0.999 \\
\hline AGFI & $>0.8$ & 0.984 & 0.964 & 0.976 & 0.990 & 0.997 \\
\hline SRMR & $<0.05$ & 0.008 & 0.012 & 0.012 & 0.004 & 0.008 \\
\hline RMSEA & $<0.1$ & 0.039 & 0.081 & 0.057 & 0.000 & 0.000 \\
\hline NFI & $>0.9$ & 0.997 & 0.994 & 0.995 & 0.999 & 0.999 \\
\hline CFI & $>0.9$ & 0.999 & 0.996 & 0.997 & 1.000 & 1.000 \\
\hline
\end{tabular}

$\mathrm{df}=$ degrees of freedom; GFI = goodness-of-fit index; AGFI = adjusted GFI; SRMR = standardized root mean square residual; NFI = normed fit index; CFI = comparative fit index.

Table 4. Statistical results for the reliability and convergent validity of the measurement model for the latent variables of user knowledge, personal experience, community markers, and the brand equity of florists based on data generated from 410 valid online questionnaires that were sampled during the period of 3 May 2018 to 4 Nov. 2018 from the fan base of the Facebook brand pages established by the florists located in Taiwan.

\begin{tabular}{|c|c|c|c|c|c|}
\hline Variables & $\begin{array}{l}\text { Standardized } \\
\text { factor } \\
\text { loadings }\end{array}$ & $\begin{array}{c}\text { Error } \\
\text { variance }\end{array}$ & $\begin{array}{c}\text { Cronbach's } \\
\alpha\end{array}$ & $\begin{array}{l}\text { Composite } \\
\text { reliability } \\
(\rho c)\end{array}$ & $\begin{array}{c}\text { Avg } \\
\text { variance } \\
\text { extracted }\end{array}$ \\
\hline User knowledge & & & 0.868 & 0.858 & 0.669 \\
\hline 1. I know the history of this florist well & 0.813 & 0.354 & & & \\
\hline 3. I know the products and services provided by this florist well & 0.829 & 0.297 & & & \\
\hline Personal experience & & & 0.866 & 0.897 & 0.744 \\
\hline 1. I have a good interaction with this florist & 0.852 & 0.239 & & & \\
\hline Community markers & & & 0.891 & 0.898 & 0.690 \\
\hline 1. The florist's Facebook fan base I belong to has established its private conventions & 0.885 & 0.224 & & & \\
\hline 2. The florist's Facebook fan base I belong to has established its exclusive rituals & 0.901 & 0.179 & & & \\
\hline 3. The florists' Facebook fan base I belong to has established its own habits & 0.807 & 0.333 & & & \\
\hline 4. I am willing to fulfill my responsibility to the florist's Facebook fan base that I belong to & 0.696 & 0.493 & & & \\
\hline Perceived quality & & & 0.909 & 0.949 & 0.860 \\
\hline 1. I think this florist offers great products and services & 0.890 & 0.104 & & & \\
\hline 3. I am willing to recommend this florist to other consumers & 0.736 & 0.293 & & & \\
\hline
\end{tabular}


Table 5. Statistical results of correlations for the discriminant validity indicated by the square root of average variance extracted for the measurement model of the latent variables of user knowledge, personal experience, community markers, and the brand equity of florists based on the data generated from 410 valid online questionnaires that were sampled during the period from 3 May 2018 to 4 Nov. 2018 from the fan base of the Facebook brand pages established by the florists located in Taiwan.

\begin{tabular}{|c|c|c|c|c|c|}
\hline Variables & User knowledge & Personal experience & Community markers & Perceived quality & User loyalty \\
\hline User knowledge & $(0.818)$ & & & & \\
\hline Personal experience & 0.785 & $(0.863)$ & & & \\
\hline Community markers & 0.555 & 0.508 & $(0.831)$ & & \\
\hline Perceived quality & 0.599 & 0.734 & 0.453 & $(0.927)$ & \\
\hline User loyalty & 0.648 & 0.705 & 0.674 & 0.693 & $(0.760)$ \\
\hline
\end{tabular}

The number in parenthesis is the square root of average variance extracted.

Table 6. Statistical results of the goodness-of-fit test for the structural model proposed in this study to profile the causal relationship among the variables or constructs of user knowledge, personal experience, the formation of the florist's social media-based brand community, and the florist's brand equity based on the data generated from 410 valid online questionnaires that were sampled during the period from 3 May 2018 to 4 Nov. 2018 from the Facebook brand pages established by the florists located in Taiwan.

\begin{tabular}{lcc}
\hline $\begin{array}{l}\text { Model-fit } \\
\text { indices }\end{array}$ & $\begin{array}{c}\text { Suggested } \\
\text { value }\end{array}$ & $\begin{array}{c}\text { Estimated } \\
\text { value }\end{array}$ \\
\hline$\chi^{2} / \mathrm{df}$ & $<5.0$ & 5.455 \\
GFI & $>0.8$ & 0.841 \\
AGFI & $>0.8$ & 0.777 \\
SRMR & $<0.08$ & 0.071 \\
RMSEA & $<0.1$ & 0.104 \\
NFI & $>0.9$ & 0.897 \\
CFI & $>0.9$ & 0.914 \\
\hline
\end{tabular}

$\mathrm{df}=$ degrees of freedom; GFI = goodness-of-fit index; AGFI = adjusted GFI; SRMR = standardized root mean square residual; NFI = normed fit index; $\mathrm{CFI}=$ comparative fit index.

community $(\beta=0.528, P<0.001)$, and then of the users' loyalty toward that florist increasing with the formation of that virtual community $(\beta=0.401, P<0.001)$. The more knowledgeable the users are of the florist, the more competent the users are in terms of becoming the members of the virtual brand community for the florist. This finding is consistent with previous studies. For example, Algesheimer et al. (2005) took a European car club as a case to investigate consumer behaviors in brand communities. They found that consumers who were highly knowledgeable of the brand exhibited a higher identification and engagement toward the brand's consumer community, and they were also more likely to engage in and maintain a quality relationship with that community. Previous studies also revealed that the more likely it is that the fan base has been transformed into a brand community, the more likely it is that the brand's brand equity will increase, because the members of the fan-based brand community will subsequently be more likely to create value for the brand, such as increasing the use of the product, becoming more involved in the brand community, or spreading positive word-of-mouth for the brand. Therefore, the quality of community members' relationships with the products, brands, operators, or other consumers can be strengthened, as can their loyalty to the brand (Habibi et al., 2014, 2016; Laroche et al., 2012, 2013).
The hypothesis that users' experience with the florist drives the formation of the florist's social media-based brand community was not supported in this study, but its effect on users' perceived quality in relation to the florist was proved $(\beta=0.808, P<$ 0.001 ). Brand community is an aggregation rich in social context whereby social interaction is an essential factor for keeping the individual member linked to the group. Therefore, as individuals consider whether to join a brand community, what is of concern to the individuals is not only their attitudes toward the products or brands, but also the stress or potential risk associated with joining a social group. Therefore, the fear of not fitting in or prejudicial stereotypes may prevent users from recognizing themselves as the same kind of person, which inhibits the users from seeing themselves as a group and being transformed into a brand community to support the florist (McAlexander et al., 2002). Consequently, as indicated by the statistical results, users' experience with the florist is not influential for converting the florist's fan base into a virtual brand community, unless their experience with the florist can give them more advanced knowledge about the florist. This is due to the users' experience with the florist being highly correlated with the users' knowledge of the florist, which has been proved to significantly facilitate the formation of the florist's social media-based brand community in this study $(r=0.864, P<0.001)$.

The importance of users' knowledge in terms of converting the florist's social media fan base into a social media-based brand community might contribute to the reason why knowledge helps to eliminate individuals' stereotypes, and then to change individuals' behaviors. When McAlexander et al. (2002) investigated the factors influencing the development of brand communities, they found that the stereotype was a factor hindering consumers from participating in brand communities, but consumers' personal experiences helped enhance their knowledge of the products, brands, or communities, and could therefore eliminate the consumers' stereotype regarding the business and then increase their willingness to participate in that business's brand communities. In this study, the users' knowledge in relation to a flower shop, such as knowledge of the shop's history, credence with regard to either the shop's products or services, or its ability to protect users' personal information, may as- sist in eliminating users' stereotypes and perceived risks in terms of behaving as a brand community member on the florist's Facebook brand page.

Another reason that may explain the function of users' knowledge in relation to the formation of a florist's social media-based brand community is the building of a social network via information exchange in the community. Social interaction is the core for linking individuals together in a group. Without social interaction, community members may enter dormancy, and then eventually leave that community (Dholakia and Vianello, 2009). Therefore, whether the community can provide the social interaction function for its members is crucial for the maintenance of that community. Knowledge gives individuals an opportunity to interact with one another via learning or information sharing, and so it can help individuals to build a close social network within a group (Talja and Hansen, 2006). Therefore, in this study, the knowledge of a florist can increase the users' capacity to engage in information sharing or knowledge exchange within the florist's fan base. This can help those users to build up their social networks on the florist's brand page, and thus increase their identification with the community of the florist's social media-based fans. Besides, consumers who are highly knowledgeable about a brand usually have a stronger identification and a more positive relationship with that brand, and are thereby more willing to create positive word-of-mouth for it (Cohen and Levinthal, 1990). All these may also be a reason to explain why users' knowledge of a florist can drive the growth of the social media-based brand community and brand equity of that florist.

\section{Conclusions}

Florists gain few benefits from the adoption of social media if their page users merely continue to be online visitors or lurkers. Thus, how the users can be converted into buyers is a considerable issue for the florists. Previous studies have demonstrated that brand communities play a role in converting consumers into brand users and protecting consumer loyalty for the brand (McAlexander et al., 2002). That role is also demonstrated in a cyberspace setting, in which as the online users are more likely to engage in a virtual brand community and commit to that community, they will be more likely to be transformed into the buyers of the brand 
Table 7. Statistical results of the path analysis for the structural model proposed in this study to profile the casual relationships among the latent variables of user knowledge, personal experience, the development of the florist's social media-based brand community, and the florist's brand equity based on the data generated from 410 valid online questionnaires that were sampled during the period from 3 May 2018 to 4 Nov. 2018 from the Facebook brand pages established by the florists located in Taiwan.

\begin{tabular}{lcrrc}
\hline Path & Standardized estimate & SE & $t$ & $P$ \\
\hline User knowledge $\rightarrow$ community markers & 0.528 & 0.135 & 4.233 & $* * *$ \\
Personal experience $\rightarrow$ community markers & 0.087 & 0.138 & 0.713 & 0.476 \\
Personal experience $\rightarrow$ perceived quality & 0.808 & 0.043 & 14.792 & $* * *$ \\
Community markers $\rightarrow$ perceived quality & 0.022 & 0.032 & 0.476 & 0.634 \\
Community markers $\rightarrow$ user loyalty & 0.401 & 0.030 & 9.314 & $* * *$ \\
Perceived quality $\rightarrow$ user loyalty & 0.690 & 0.047 & 14.318 & $* * *$ \\
$* * * P<0$
\end{tabular}

$$
* * * P<0.001 \text {. }
$$

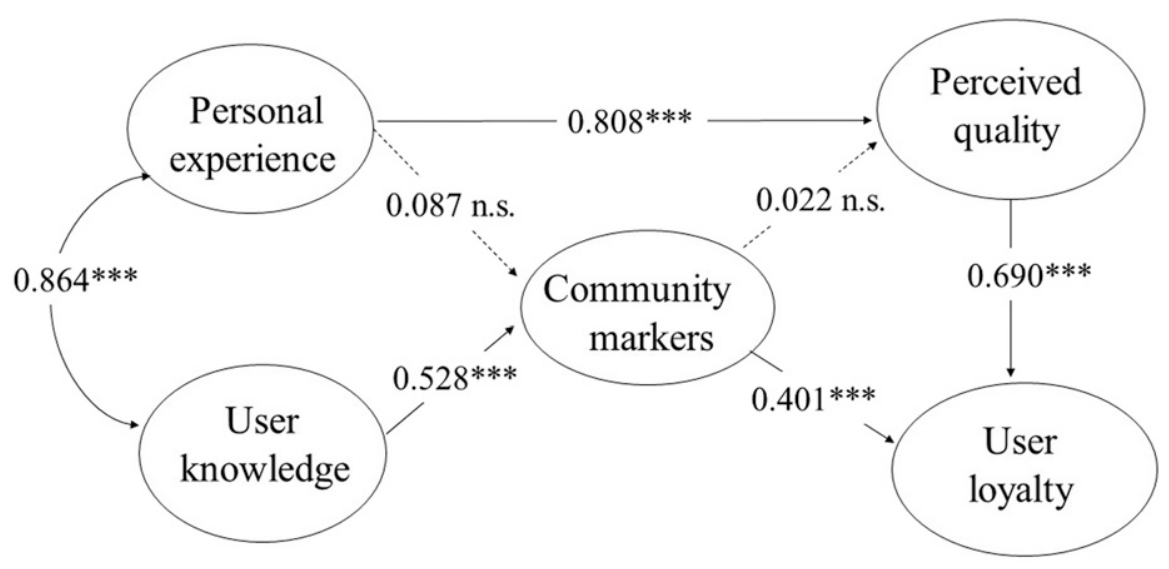

n.s. not significant at $\alpha=0.05 ; * * * P<0.001$

Fig. 1. The causal relationship among the latent variables of user knowledge, personal experience, community markers, perceived quality, and user loyalty based on 410 valid online questionnaires that were sampled during the period from 3 May 2018 to 4 Nov. 2018 from the fan base of the Facebookbrand pages established by the florists located in Taiwan.

(Gupta et al., 2010). Obviously, virtual brand communities serve as an intermediary in the process of converting page users into online buyers. This study has examined the formation of the florist's social media-based brand community and looked at the antecedents that drive the formation to occur. This study has proved the potential of building a florist's virtual brand community from the florist's social media fan base with the finding that the current florist's fan base exhibits the features of brand communities in terms of a shared consciousness, shared rituals and traditions, and an obligation to the community. This study has also revealed that users' knowledge of the florist is an antecedent for facilitating the transformation of the florists' social media fan base into a virtual brand community for the florist. The study's results imply that the florists can foster their virtual brand communities from their social media fan base via improving their users' knowledge of them. Based on these findings, the author provides the following suggestions regarding ways in which the florists can extend the efficiency of their social media use in marketing:

1. Converting the florist's social media fan base into a brand community by integrating the online and offline activities that enrich the users' knowledge of the florist. This study found that users' experience with a florist is highly corre- lated with the users' knowledge of the florist, and that the users' knowledge of the florist has a direct effect on the transformation of the florist's social media fan base into a virtual brand community for the florist. These results are consistent with previous findings that consumers' product-related experience has a positive effect on the consumers' subjective knowledge (Park et al., 1994), and the consumers' subjective knowledge significantly drives consumers to voluntarily share information online (Yuan et al., 2016), a behavior that is beneficial to the formation of brand communities (McAlexander et al., 2002). Therefore, to facilitate the formation of the florist's social media-based brand community, florists can integrate their online and offline strategies with a focus on improving the quality and quantity of their fans' knowledge about them. For example, florists can organize certain offline events, such as an open house, workshops, and user group rallies for charities or community service, etc., and invite their page users to participate (McAlexander et al., 2002). These activities not only facilitate the social interaction between the users and the florist, but also allow the users to engage in information exchange among themselves so that they can retain new knowl- edge/skills to improve their product use. In particular, offline events enable users to have a shared experience, which has been demonstrated to improve the relationships among them, being conducive to the formation of brand communities (McAlexander and Schouten, 1998; McAlexander et al., 2002; Zaglia, 2013). As consumers who purchase horticultural products online are often the same people who visit the offline flower shops (Behe et al., 2008), the florist's online business should not be planned from the aspect of cyberspace alone, but should be mutually constructed with offline activities to improve the synergy.

2. Facilitating the formation of the florist's social media-based brand community via maintaining a quality relationship with the established customers. The finding that users' knowledge significantly facilitated the formation of the florist's social media-based brand community implies the importance of established customers to the formation of the florist's social media-based brand community, an implication resonating with the argument put forward by Algesheimer et al. (2005). Established customers are usually the consumers who are loyal and have a stronger identification with the brand. Theoretically, they are more knowledgeable about the brand, and so they are expected to be more likely to play the role of veterans to influence other users' knowledge of and identification with the florist (McAlexander et al., 2002). With regard to the conversion of the florist's social media fan base into virtual brand communities, the florists need to develop incentive strategies to encourage their established customers to remain in the fan base, as well as to create events to evoke social interaction or information exchange between the new visitors and established customers on their social media pages.

This study has demonstrated the possibility of taking social media as a mediator for fostering a virtual brand community to support the business of a florist. It is hoped that subsequent studies will explore more factors beyond the users' knowledge and personal experience that will facilitate the formation of the florists' social media-based brand communities, which can bring multiple benefits to the florists.

\section{Literature Cited}

Abed, S.S., Y.K. Dwivedi, and M.D. Williams. 2015. Social media as a bridge to e-commerce adoption in SMEs: A systematic literature review. Mktg. Rev. 15(1):39-57.

Akar, E. and B. Topçu. 2011. An examination of the factors influencing consumers' attitudes toward social media marketing. J. Internet Commerce 10:35-67.

Algesheimer, R., U.M. Dholakia, and A. Herrmann. 2005. The social influence of brand community: Evidence from European car clubs. J. Mktg. 69(3):19-34. 
Anderson, J. and D. Gerbing. 1988. Structural equation modeling in practice: A review and recommended two-step approach. Psychol. Bull. 103(3):411-423.

Bagozzi, R. and Y. Yi. 1988. On the evaluation of structural equation models. J. Acad. Mktg. Sci. 16(1):74-94.

Behe, B.K., B. Harte, and C. Yue. 2008. Online gardening search activities and purchases. J. Environ. Hort. 26(4):210-216.

Bentler, P.M. and D.G. Bonett. 1980. Significance tests and goodness-of-fit in the analysis of covariance structures. Psychol. Bull. 88:588-606.

Bollen, K.A. 1989. Structural equations with latent variables. John Wiley, New York, NY.

Browne, M.W. and R. Cudeck. 1993. Alternative ways of assessing model fit, p. 136-192. In: K.A. Bollen and J.S. Long (eds.). Testing structural equation models. Sage, Newbury Park, CA.

Brucks, M. 1985. The effects of product class knowledge on information search behavior. J. Consum. Res. 12:1-16.

Chi, H.H. 2011. Interactive digital advertising vs. virtual brand community: Exploratory study of user motivation and social media marketing responses in Taiwan. J. Interact. Advert. 12(1):44-61.

Cohen, W.M. and D.A. Levinthal. 1990. Absorptive capacity: A new perspective on learning and innovation. Admin. Sci. Qrtly. 35(1): 128-152.

Datareportal. 2019. Digital 2019: Global digital overview. 19 Jan. 2020. <https://datareportal.com/ reports/digital-2019-global-digital-overview $>$.

Dholakia, U.M. and S. Vianello. 2009. Effective brand community management: Lessons from customer enthusiasts. SSRN Electronic J., doi: 10.2139/ssrn. 1512090 .

Doll, W.J., W. Xia, and G. Torkzadeh. 1994. A confirmatory factor analysis of the end-user computing satisfaction instrument. MIS Qrtly 18(4):453-461.

Drury, G. 2008. Opinion piece: Social media: Should marketers engage and how can it be done effectively? J. Direct Data Digital Mktg. Practice 9(3):274-277.

Fornell, C. and D. Larcker. 1981. Evaluating structural equation models with unobservable variables and measurement error. J. Mktg. Res. 18:39-50.

Fuchs, C. 2014. Social media: A critical introduction. Sage, London.

Garver, M.S. and J.T. Mentzer. 1999. Logistics research methods: Employing structural equation modeling to test for construct validity. J. Bus. Logist. 20(1):33-57.

George, D. and P. Mallery. 2003. SPSS for Windows step by step: A simple guide and reference. 11.0 update. 4th ed. Allyn \& Bacon, Boston, MA.

Goh, K.Y., C.S. Heng, and Z. Lin. 2013. Social media brand community and consumer behavior: Quantifying the relative impact of user- and marketer-generated content. Inf. Syst. Res. 24(1):88-107.

Gupta, S., H.W. Kim, and S.J. Shin. 2010. Converting virtual community members into online buyers. Cyberpsychol. Behav. Soc. Netw. 13(5):513-520.

Habibi, M.R., M. Laroche, and M.O. Richard. 2014. The roles of brand community and community engagement in building brand trust on social media. Comput. Human Behav. 37:152161.

Habibi, M.R., M. Laroche, and M.O. Richard. 2016. Testing an extended model of consumer behavior in the context of social media-based brand communities. Comput. Human Behav. 62:292-302

Hair, J.F., Jr., R.E. Anderson, R.L. Tatham, and W.C. Black. 2010. Multivariate data analysis: A global perspective. Prentice Hall, Upper Saddle River, NJ.

Hu, L. and P.M. Bentler. 1999. Cutoff criteria for fit indexes in covariance structure analysis: Conventional criteria versus new alternatives. Struct. Equ. Modeling 6(1):1-55.

Huang, L. and L. Chen. 2018. Message strategies and media formats of florists' Facebook posts and their effects on users' engagement behaviors. HortScience 53:1647-1654.

Jöreskog, K.G. and D. Sörbom. 1996. LISREL 8: User's reference guide. Scientific Software International, Chicago, IL.

Kaplan, A.M. and M. Haenlein. 2010. Users of the world, unite! The challenges and opportunities of social media. Bus. Horiz. 53(1):59-68.

Kline, R.B. 2015. Principles and practice of structural equation modeling. Guilford Publications, New York, NY.

Laroche, M., M.R. Habibi, and M.O. Richard. 2013. To be or not to be in social media: How brand loyalty is affected by social media? Intl. J. Inf. Mgt. 33(1):76-82.

Laroche, M., M.R. Habibi, M.O. Richard, and R. Sankaranarayanan. 2012. The effects of social media based brand communities on brand community markers, value creation practices, brand trust and brand loyalty. Comput. Human Behav. 28:1755-1767.

MacCallum, R.C. and S. Hong. 1997. Power analysis in covariance structure modeling using GFI and AGFI. Multivariate Behav. Res. 32: 193-210.

McAlexander, J.H. and J.W. Schouten. 1998 Brandfests: Servicescapes for the cultivation of brand equity. Servicescapes: The concept of place in contemporary markets 377:377-402.

McAlexander, J.H., J.W. Schouten, and H.F Koenig. 2002. Building brand community. J. Mktg. 66(1):38-54.

McDonald, R.P. and M.R. Ho. 2002. Principles and practice in reporting structural equation analysis. Psychol. Methods 7:64-82.

Muniz, A.M. and T.C. O'Guinn. 2001. Brand community. J. Consum. Res. 27(4):412-432.
NapoleonCat, Inc. 2019. Facebook users in TaiwanDec. 2019. 7 Jan. 2020. <https://napoleoncat. $\mathrm{com} /$ stats/facebook-users-in-taiwan/2019/12>.

Ortiz-Ospina, E. 2019. The rise of social media. 19 Jan. 2020. <https://ourworldindata.org/rise-ofsocial-media $>$.

Park, C.W., D.L. Mothersbaugh, and L. Feick. 1994. Consumer knowledge assessment. J. Consum. Res. 21:71-82.

Prince, T.L. and T.A. Prince. 2014. Florists broadly adopt social media. Payoff somewhat nil. Now what? 22 Apr. 2016. <http://flowersandcents.com/wp-content/uploads/2014/03/ Florists-SocialMedia-2.pdf $>$.

Russell Research. 2016. 2016 Generations of flowers study. Russell Res., Inc., East Rutherford, NJ.

Schimmenti, E., A. Galati, V. Borsellino, C. Ievoli, C. Lupi, and S. Tinervia. 2013. Behaviour of consumers of conventional and organic flowers and ornamental plants in Italy. HortScience 40:162-171.

Schmitt, B. and L. Zarantonello. 2013. Consumer experience and experiential marketing: A critical review. Rev. Mktg Res. 10:25-61.

Schumacker, R.E. and R.G. Lomax. 2004. A beginner's guide to structural equation modeling. 2nd ed. Lawrence Erlbaum Associates, Mahwah, NJ.

Simon, F. and V. Tossan. 2018. Does brandconsumer social sharing matter? A relational framework of customer engagement to brandhosted social media. J. Bus. Res. 85:175-184.

Statista. 2019. Most popular social networks worldwide as of July 2019, ranked by number of active users (in millions). 24 Oct. 2019. <https:/ www.statista.com/statistics/272014/globalsocial-networks-ranked-by-number-of-users/>.

Tajfel, H. 1982. Social psychology of intergroup relations. Annu. Rev. Psychol. 33(1):1-39.

Talja, S. and P. Hansen. 2006. Information sharing, p. 113-134. In: A. Spink and C. Cole (eds.). New directions in human information behavior. Springer Science \& Business Media, the Netherlands.

Torres, A.P., S.S. Barton, and B.K. Behe. 2019. Evaluating the business and owner characteristics influencing the adoption of online advertising strategies in the green Industry. HortTechnology 29:374-381.

Tzavaras, M., I. Tzimitra-Kalogianni, and M. Bourlakis. 2010. Consumer behaviour in the Greek floral market: Comparative insights for the food industry. Brit. Food J. 112(4):403-415.

Yuan, C.H. 2010. Applying the unified theory of acceptance and use of technology to study the effect of customer intention and its relevant factors on the online florists (in Chinese). Chinese Cult. Univ., Taipei, MBA Thesis.

Yuan, D., Z. Lin, and R. Zhuo. 2016. What drives consumer knowledge sharing in online travel communities? Personal attributes or e-service factors? Comput. Human Behav. 63:68-74.

Zaglia, M.E. 2013. Brand communities embedded in social networks. J. Bus. Res. 66(2):216-223. 